\title{
Factors predictive of relapse in adult bacterial osteomyelitis of long bones.
}

\author{
E. Garcia del Pozo ${ }^{1}$, J. Collazos ${ }^{2}$, J. A. Carton ${ }^{3,4}$, D. Camporro ${ }^{1}$ and V. Asensi ${ }^{3,4^{*}}$ (D)
}

\begin{abstract}
Background: Osteomyelitis is a difficult-to-cure infection with a high relapse rate despite combined medical and surgical therapies. Some severity factors, duration of antimicrobial therapy and type of surgical procedure might influence osteomyelitis relapse.

Methods: 116 patients with osteomyelitis were followed for $\geq 1$ year after hospital discharge. Demographic, microbiological and clinical data, eight severity factors and treatment (surgical and antibiotic) were analyzed.

Results: Mean age was 53 years and $74.1 \%$ were men. Tibia (62.1\%) and S. aureus (58.5\%) were the most commonly involved bone and bacteria, respectively. Mean follow-up was 67.1 months. Forty-six patients underwent bone debridement, 61 debridement plus flap coverage and 9 antimicrobial therapy only. Twenty-six patients (22.4\%) relapsed, at a mean of 11.2 months since hospital discharge. Duration $>3$ months $(p=0.025)$, number of severity factors $(P=0.02)$ and absence of surgery $(P=0.004)$ were associated with osteomyelitis relapse in the univariate analysis. In the Cox regression analysis, osteomyelitis duration $>3$ months $(P=0.012)$, bone exposure $(P=0.0003)$ and type of surgery $(P<0.0001)$ were associated with relapse. Regarding the surgical modalities, bone debridement with muscle flap was associated with better osteomyelitis outcomes, as compared with no surgery $(P<0.0001)$ and debridement only $(P=0.004)$.
\end{abstract}

Conclusions: Osteomyelitis extending for $>3$ months, bone exposure and treatment other than surgical debridement with muscular flap are risk factors for osteomyelitis relapse.

Keywords: Osteomyelitis, Relapse, Severity factors, Debridement, Muscular flap, Antibiotics

\section{Background}

Osteomyelitis is a difficult-to-treat bone infection characterized by progressive and inflammatory destruction of the infected bone and new apposition of bone at the site of infection. In adults, osteomyelitis is usually a complication of open wounds due to fractures, surgery, or both. The risk and severity of the infection can be enhanced by the presence of foreign bodies (metallic or prosthetic devices). It is reported that 0.4 to $7 \%$ of trauma and orthopedic interventions are complicated by osteomyelitis [1-6]. This infection can develop as well in non-injured bones after bacteremia, mostly in prepubertal children and in elderly patients, in which the

\footnotetext{
*Correspondence: vasensia@gmail.com

${ }^{3}$ Infectious Diseases Unit, Hospital Universitario Central de Asturias (HUCA),

Oviedo University School of Medicine, Oviedo, Spain

${ }^{4}$ Group of Translational Research in Infectious Diseases, Instituto de

Investigación Sanitaria del Principado de Asturias (ISPA), Asturias, Spain

Full list of author information is available at the end of the article
}

infection involves mostly the axial skeleton. Staphylococcus aureus is the microorganism most frequently isolated in both posttraumatic and hematogenous osteomyelitis. Despite appropriate combined medical and surgical therapies, recurrences are common, often in the range of $20-30 \%$, causing significant morbidity and mortality, as well as major economic losses [7-11].

The features associated with osteomyelitis relapse, as well as their relative weights have not been clearly demonstrated so far, and their identification might be important in order to optimize antimicrobial and surgical therapies in those patients prone to relapse. Among these features, a number of demographic, laboratory, clinical, microbiological and therapeutic, both antibiotic and surgical, factors might be potentially involved. On the other hand, the identification of possible factors of severity at the time of presentation that could influence

(c) The Author(s). 2018 Open Access This article is distributed under the terms of the Creative Commons Attribution 4.0 International License (http://creativecommons.org/licenses/by/4.0/), which permits unrestricted use, distribution, and 
the outcome would be highly desirable. However, these factors remain largely unknown.

Therefore, the aim of this study was to evaluate the parameters associated with relapse in patients with osteomyelitis of long bones from a single center and, particularly, to evaluate the possible influence on the outcome of certain, predefined severity factors.

\section{Patients and methods}

\section{Patients}

Adult patients with a diagnosis of bacterial osteomyelitis of the long bones, who were admitted to the Hospital Universitario Central de Asturias (HUCA) between January 1st 1994 and October 1st 2015, and who were followed-up for at least one year after discharge, were included in the study. HUCA is a 900 bed, third-level academic hospital that provides health coverage to one million people from the region of Asturias, Northwestern Spain. Open bone fractures of long bone were classified according to Gustilo-Anderson [12].

Osteomyelitis was diagnosed using clinical and roentgenographic findings. The demonstration of bone sequestra and/or sinus tract in bone X-ray, computed tomography (CT), or magnetic resonance imaging (MRI), a positive $\mathrm{Ga}^{67}$ uptake bone scan, or a positive culture of the sequestra or sinus tract were considered diagnostic of osteomyelitis [3-7]. Osteomyelitis patients with no history of trauma or bone surgery, no lower limb vascular insufficiency, and without a contiguous focus of infection were considered to have hematogenous osteomyelitis.

Patients with osteo-articular tuberculosis were excluded. Osteomyelitis was considered cured if no relapse was detected during the follow-up. Surgical and sinus tract pus samples were cultured and erythrocyte sedimentation rate (ESR) and C-reactive protein (C-RP) were also recorded. A number of demographic, clinical, microbiological and therapeutic data, including the type and duration of antibiotic therapy and the modality of surgical procedure used, were also collected. Eight predefined local and systemic severity factors for osteomyelitis were considered: relapse of prior osteomyelitis, duration $>3$ months, presence of osteosynthesis material, bone exposure, peripheral vascular involvement, diabetes, multiresistant/polymicrobial infection and immunosuppression. All the study data were introduced into a database and analyzed from October 2016 onwards, one year after the ending of the inclusion period.

\section{Statistical analysis}

Continuous variables are reported as mean $(95 \% \mathrm{CI})$ and categorical variables as $\mathrm{n}(\%)$. The comparisons between the relapse and non-relapse cases were carried out by the $t$-test and the chi-square or Fisher exact tests when appropriate, for continuous and categorical variables, respectively. Kaplan-Meier survival curves were used to evaluate the relationships of the different severity factors with the outcome, and their statistical significance was assessed by means of the log-rank test. A stepwise logistic regression analysis was carried out to evaluate the relative importance of each severity factor, in order to elaborate a predictive formula of the outcome. The result of this formula was tested by means of a receiver operating characteristic (ROC) curve, and the area under the ROC curve was also calculated. A stepwise Cox regression analysis was constructed to identify the variables independently associated with the relapse of osteomyelitis. SPSS v.22 software was used for statistical calculations. A $P$ value $<0.05$ for a two-sided test was considered statistically significant.

\section{Results}

A total of 116 patients with osteomyelitis of long bones of the arms and legs, were analyzed. The mean age was 53.0 years (95\% CI $49.8-56.2$ ) and 86 of them (74.1\%) were men. Osteomyelitis was secondary to open fractures in 54 (46.6\%) patients: Gustilo-Anderson type I 18 (33.3\%), type II a 7 (13.0\%), type II b 24 (44.4\%) and III c 5 patients $(9.3 \%)$. The mean period of follow-up was 67.1 months (95\% CI 57.3-76.9 months). During this period there were 26 relapses $(22.4 \%)$, which occurred at a mean of 11.2 months (95\% CI 3.3-19.1 months) since hospital discharge. Among the relapses 6 (23.1\%) might be treatment failures. Although the attending doctor considered these 6 osteomyelitis cases as cured, a clear disappearance of clinical symptoms and/or roentgenographic findings and/or normalized C-RP and ESR values at the end of therapy was not registered in the medical charts. Of the remaining 20 patients a relapse was registered within the first year after finishing therapy in $12(46.2 \%)$ and more than one year after in other 8 patients (30.8\%).

The bone most commonly involved was the tibia (62.1\% of cases), and the most commonly isolated bacteria was Staphylococcus aureus (58.5\% of the positive cultures). Imaging studies other than simple radiographs were used in $56.3 \%$ of the patients, C-RP was elevated in $43.2 \%$ and ESR in $89.4 \%$ of the osteomyelitis patients. The time elapsed since diagnosis and treatment until the evaluation in October 2016 did not have any influence on the outcome $(P=0.8)$.

Table 1 shows the demographical, clinical, microbiological and therapeutic features of the osteomyelitis cases. There were significant differences between the patients who relapsed and those who did not relapse regarding the duration of symptoms, number of severity factors, and absence of surgical treatment. On the contrary, there were no significant differences in aspects 
Table 1 Demographic, clinical, microbiological and therapeutic features of the patients according to the outcome

\begin{tabular}{|c|c|c|c|c|}
\hline & & Relapse $(n=26)$ & No relapse $(n=90)$ & $P$ \\
\hline \multirow[t]{2}{*}{ Gender } & Male & $16(18.6 \%)$ & $70(81.4 \%)$ & \multirow[t]{2}{*}{0.096} \\
\hline & Female & $10(33.3 \%)$ & $20(66.7 \%)$ & \\
\hline Age & Years & $57.42(51.13-63.72)$ & $51.67(47.93-55.40)$ & 0.14 \\
\hline \multirow[t]{3}{*}{ Origin/source } & Hematogenous & $4(20.0 \%)$ & $16(80.0 \%)$ & \multirow[t]{3}{*}{0.5} \\
\hline & Post-traumatic & $12(19.4 \%)$ & $50(80.6 \%)$ & \\
\hline & Post-surgical & $10(29.4 \%)$ & $24(70.6 \%)$ & \\
\hline \multirow[t]{6}{*}{ Bones involved } & Femur & $6(22.2 \%)$ & $21(77.8 \%)$ & \multirow[t]{6}{*}{0.9} \\
\hline & Tibia & $17(23.6 \%)$ & $55(76.4 \%)$ & \\
\hline & Fibula & $1(16.7 \%)$ & $5(83.3 \%)$ & \\
\hline & Humerus & $0(0 \%)$ & $3(100 \%)$ & \\
\hline & Ulna & $1(20.0 \%)$ & $4(80.0 \%)$ & \\
\hline & Radius & $1(33.3 \%)$ & $2(66.7 \%)$ & \\
\hline \multirow[t]{2}{*}{ Imaging (other than radiographs) } & Yes & $20(28.2 \%)$ & $51(71.8 \%)$ & \multirow[t]{2}{*}{0.06} \\
\hline & No & $6(13.3 \%)$ & $39(86.7 \%)$ & \\
\hline C Reactive Protein (C-RP) & $\mathrm{mg} / \mathrm{L}$ & $8.865(.357-17.373)$ & $6.440(4.739-8.1395)$ & 0.6 \\
\hline Erythrocyte sedimentation rate (ESR) & $\mathrm{mm} / \mathrm{h}$ & $53.52(37.26-69.78)$ & $65.01(57.20-72.82)$ & 0.18 \\
\hline Duration of follow-up & Months & $56.12(37.80-74.43)$ & $70.28(58.67-81.89)$ & 0.24 \\
\hline \multicolumn{5}{|l|}{ Severity factors } \\
\hline \multirow[t]{2}{*}{ Relapse of previous osteomyelitis } & Yes & $14(28.6 \%)$ & $35(71.4 \%)$ & \multirow[t]{2}{*}{0.17} \\
\hline & No & $12(17.9 \%)$ & $55(82.1 \%)$ & \\
\hline \multirow[t]{2}{*}{ Symptoms longer than 3 months } & Yes & $22(28.6 \%)$ & $55(71.4 \%)$ & \multirow[t]{2}{*}{0.025} \\
\hline & No & $4(10.3 \%)$ & $35(89.7 \%)$ & \\
\hline \multirow[t]{2}{*}{ Presence of osteosynthesis material } & Yes & $13(22.0 \%)$ & $46(78.0 \%)$ & \multirow[t]{2}{*}{0.9} \\
\hline & No & $13(22.8 \%)$ & $44(77.2 \%)$ & \\
\hline \multirow[t]{2}{*}{ Bone exposure } & Yes & $12(26.1 \%)$ & $34(73.9 \%)$ & \multirow[t]{2}{*}{0.4} \\
\hline & No & $14(20.0 \%)$ & $56(80.0 \%)$ & \\
\hline \multirow[t]{2}{*}{ Vascular involvement } & Yes & $5(45.5 \%)$ & $6(54.5 \%)$ & \multirow[t]{2}{*}{0.067} \\
\hline & No & $21(20.0 \%)$ & $84(80.0 \%)$ & \\
\hline \multirow[t]{2}{*}{ Diabetes } & Yes & $3(30.0 \%)$ & $7(70.0 \%)$ & \multirow[t]{2}{*}{0.7} \\
\hline & No & $23(21.7 \%)$ & $83(78.3 \%)$ & \\
\hline \multirow[t]{2}{*}{ Multiresistant/polymicrobial infection } & Yes & $12(23.5 \%)$ & $39(76.5 \%)$ & \multirow[t]{2}{*}{0.8} \\
\hline & No & $14(21.5 \%)$ & $51(78.5 \%)$ & \\
\hline \multirow[t]{2}{*}{ Immunosuppression } & Yes & $2(50.0 \%)$ & $2(50.0 \%)$ & 0.22 \\
\hline & No & $24(21.4 \%)$ & $88(78.6 \%)$ & \\
\hline Presence of severity factors & Yes & $12(29.3 \%)$ & $29(70.7 \%)$ & 0.19 \\
\hline & No & $14(18.7 \%)$ & $61(81.3 \%)$ & \\
\hline Types of severity factors & No & $14(18.7 \%)$ & $61(81.3 \%)$ & 0.4 \\
\hline & Local & $5(22.7 \%)$ & $17(77.3 \%)$ & \\
\hline & Systemic & $4(40.0 \%)$ & $6(60.0 \%)$ & \\
\hline & Both & $3(33.3 \%)$ & $6(66.7 \%)$ & \\
\hline Number of severity factors & & $3.19(2.69-3.69)$ & $2.49(2.2-2.76)$ & 0.02 \\
\hline Microbiology & & & & \\
\hline Gram-positive cocci $^{\text {a }}$ & Gram-positive cocci & $17(24.6 \%)$ & $52(75.4 \%)$ & 0.8 \\
\hline & Others & $6(27.3 \%)$ & $16(72.7 \%)$ & \\
\hline
\end{tabular}


Table 1 Demographic, clinical, microbiological and therapeutic features of the patients according to the outcome (Continued)

\begin{tabular}{|c|c|c|c|c|}
\hline & & Relapse $(n=26)$ & No relapse $(n=90)$ & $P$ \\
\hline \multirow[t]{2}{*}{ Gram-negative bacilli ${ }^{a}$} & Gram-negative bacilli & $9(28.1 \%)$ & $23(71.9 \%)$ & 0.8 \\
\hline & Others & $15(25.4 \%)$ & $44(74.6 \%)$ & \\
\hline \multirow[t]{2}{*}{ Staphylococcus aureus ${ }^{a}$} & S aureus & $12(25.0 \%)$ & $36(75.0 \%)$ & 0.9 \\
\hline & Others & $8(23.5 \%)$ & $26(76.5 \%)$ & \\
\hline \multirow[t]{2}{*}{ Gram-pos cocci vs Gram-neg bacilli ${ }^{\text {a }}$} & Gram-positive cocci & $14(25.0 \%)$ & $42(75.0 \%)$ & 0.8 \\
\hline & Gram-negative bacilli & $6(27.3 \%)$ & $16(72.7 \%)$ & \\
\hline \multicolumn{5}{|l|}{ Treatment } \\
\hline \multirow[t]{2}{*}{ Type of treatment } & Antibiotics only & $6(66.7 \%)$ & $3(33.3 \%)$ & 0.004 \\
\hline & Antibiotics plus surgery & $20(18.7 \%)$ & $87(81.3 \%)$ & \\
\hline \multirow[t]{2}{*}{ Intravenous beta-lactams } & $\beta$-lactams & $5(13.9 \%)$ & $31(86.1 \%)$ & 0.7 \\
\hline & Other antibiotics & $4(18.2 \%)$ & $18(81.8 \%)$ & \\
\hline \multirow[t]{2}{*}{ Oral $\beta$-lactams } & $\beta$-lactams & $4(23.5 \%)$ & $13(76.5 \%)$ & 0.7 \\
\hline & Other antibiotics & $9(17.3 \%)$ & $43(82.7 \%)$ & \\
\hline \multirow[t]{2}{*}{ Oral clindamycin } & Clindamycin & $3(10.7 \%)$ & $25(89.3 \%)$ & 0.21 \\
\hline & Other antibiotics & $11(22.0 \%)$ & $39(78.0 \%)$ & \\
\hline \multirow[t]{2}{*}{ Oral rifampin } & Rifampin & $4(15.4 \%)$ & $22(84.6 \%)$ & 0.8 \\
\hline & Other antibiotics & $10(19.2 \%)$ & $42(80.8 \%)$ & \\
\hline Duration of intravenous antibiotics & Days & $26.44(23.24-29.64)$ & $29.33(27.09-31.58)$ & 0.21 \\
\hline Total duration of antibiotic treatment & Days & $80.76(36.05-125.47)$ & $69.58(62.66-76.49)$ & 0.40 \\
\hline \multirow[t]{3}{*}{ Type of surgery } & None & $6(66.7 \%)$ & $3(33.3 \%)$ & 0.004 \\
\hline & Debridement & $9(19.6 \%)$ & 37 (80.4\%) & \\
\hline & Debridement and flap & $11(18.0 \%)$ & $50(82.0 \%)$ & \\
\hline \multirow[t]{2}{*}{ Removal of osteosynthesis material ${ }^{b}$} & Yes & $8(19.0 \%)$ & $34(81.0 \%)$ & 0.24 \\
\hline & No & $4(36.4 \%)$ & $7(63.6 \%)$ & \\
\hline \multirow[t]{5}{*}{ Type of surgical reconstruction } & None & $15(27.3 \%)$ & $40(72.7 \%)$ & 0.6 \\
\hline & Free muscle flap & $2(14.3 \%)$ & $12(85.7 \%)$ & \\
\hline & Pedicled muscle flap & $4(19.0 \%)$ & $17(81.0 \%)$ & \\
\hline & Free fasciocutaneous flap & $5(23.8 \%)$ & $16(76.2 \%)$ & \\
\hline & Pedicled fasciocutaneous flap/rotation & $0(0 \%)$ & $5(100 \%)$ & \\
\hline \multirow[t]{2}{*}{ Surgical reconstruction } & Yes (all types of flaps) & $11(18.0 \%)$ & 50 (82.0\%) & 0.23 \\
\hline & No & $15(27.3 \%)$ & 40 (72.7\%) & \\
\hline
\end{tabular}

Values are expressed as mean $(95 \% \mathrm{Cl})$ or $\mathrm{n}(\%)$ as appropriate

${ }^{a}$ The comparisons of microorganisms/antibiotics have been carried out only in the cases in which the bacteria/antibiotic have been identified

${ }^{b}$ Only in patients who had osteosynthesis material

such as demography, source of infection, bones involved, acute phase reactants, microbiology or type or duration of antibiotic treatment. No differences in relapse rate between those with methicillin-resistant (MRSA) and methicillin-susceptible Staphylococcus aureus (MSSA) osteomyelitis were observed either (data not shown in Table 1).

Figure 1 shows the Kaplan Meier survival curves for each of the 8 severity factors evaluated. A logistic regression analysis was carried out to construct a formula in order to predict the risk of relapse based solely on the severity factors studied. The resulting formula was: 1.5 points (if the patient had symptoms for longer than 3 months) +0.5 points (if there was bone exposure) +1.2 points (if there was peripheral vascular involvement) +2.0 points (if the patient was immunosuppressed) +0.2 points (if there was osteosynthesis material).

Figure 2 depicts the ROC curve for the result of the application of that formula. The application of that formula differentiates relapsing and not relapsing patients with different sensitivities and specificities depending on the cut-off used. Higher cut-offs are associated with progressively higher sensitivities and lower specificities, whereas the opposite occurs in the case of lower 

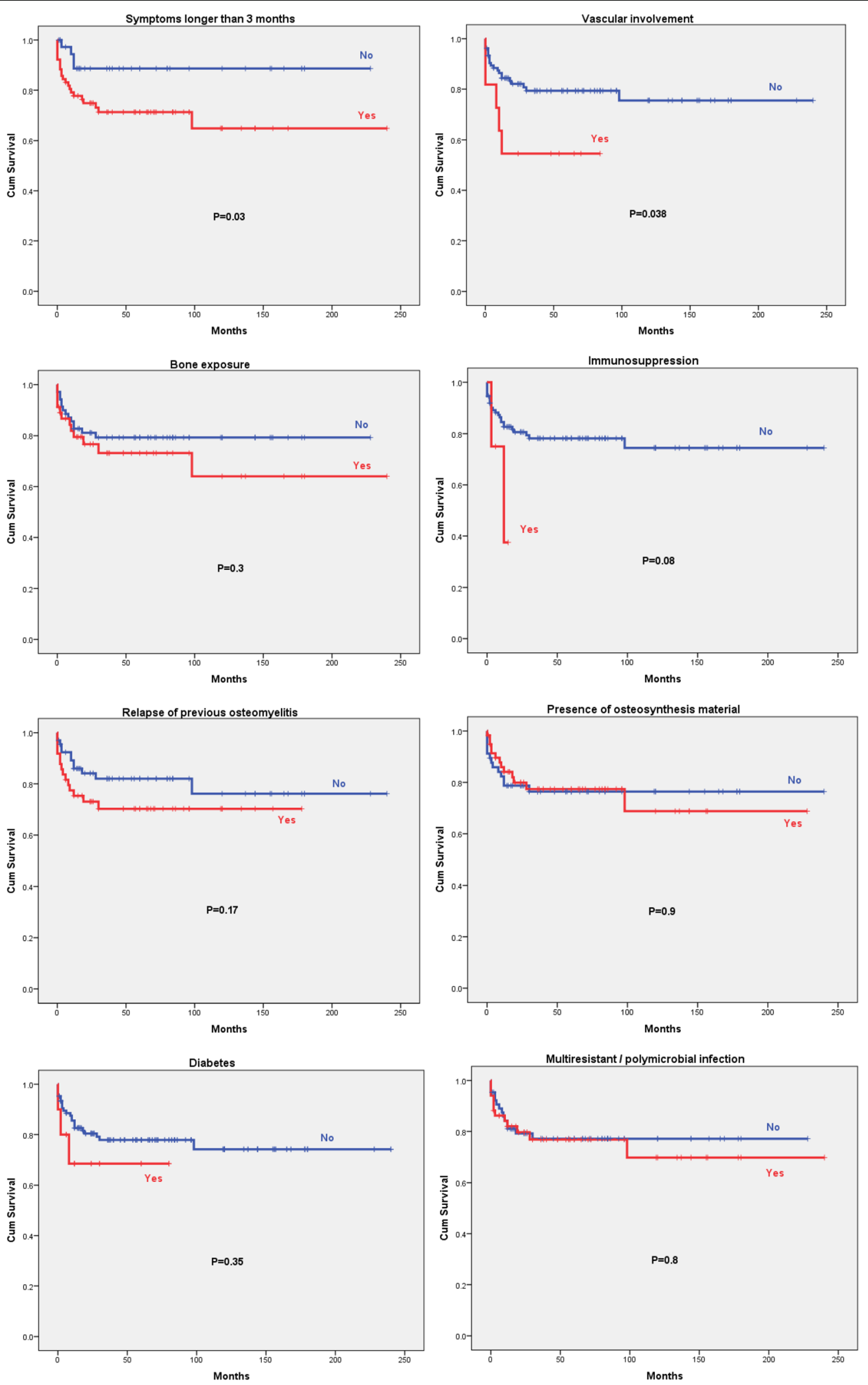

Fig. 1 Kaplan Meier cumulative survival curves of the eight severity factors for osteomyelitis 




Fig. 2 Receiver operating characteristic (ROC) curve corresponding to the predictive formula

cut-offs. Figure 2 depicts the resulting ROC curve which had an area under the curve was of 0.742 (95\% CI 0.644-0.839, $P=0.0002)$. According to this formula a score of $\geq 1.5$ points would be associated with a probability of relapse of $30.5 \%$ (positive likelihood ratio 1.52 , $95 \%$ CI 1.28-1.81), a score of $\geq 2$ points with a probability of $40.6 \%$ (positive likelihood ratio 2.37 , 95\% CI $1.52-$ 3.69 ) and a score of $\geq 2.5$ with a probability of $45.5 \%$ (positive likelihood ratio 2.88, 95\% CI 1.31-6.34).

The area under the ROC curve was 0.742 (95\% CI 0.644-0.839), $P=0.0002$ ). According to this formula a score of $\geq 1.5$ points would be associated with a probability of relapse of $30.5 \%$ (positive likelihood ratio $1.52,95 \%$ CI $1.28-1.81$ ), a score of $\geq 2$ points with a probability of $40.6 \%$ (positive likelihood ratio 2.37, $95 \%$ CI $1.52-3.69$ ) and a score of $\geq 2.5$ with a probability of $45.5 \%$ (positive likelihood ratio 2.88, $95 \%$ CI 1.31-6.34).

A Cox regression model was constructed using the variables with a $P$ value $\leq 0.2$ in the univariate analysis, as well as others of clinical relevance, to identify the factors independently associated with the outcome of the osteomyelitis over time. According to this model, the variables predictive of relapse were: duration of symptoms longer than 3 months, bone exposure and type of surgical therapy.
Among the latter, the combined use of antibiotics plus debridement and flap coverage was the most successful modality of treatment, whereas the absence of surgical treatment was predictive of the poorest outcome (Table 2 and Fig. 3).

On the contrary, there were no statistical significant associations regarding gender $(P=0.056)$, age $(P=0.4)$, relapse of previous osteomyelitis $(P=0.8)$, presence of osteosynthesis material $(P=0.12)$, peripheral vascular involvement $(P=0.8)$, diabetes $(P=0.7)$, multiresistant bacteria or polymicrobial infection $(P=0.6)$, immunosuppression $(P=0.9)$, ESR $(P=0.3)$, imaging other than simple radiographs $(P=0.5)$, duration of intravenous antibiotic therapy $(\mathrm{P}=0.5)$, total duration of antibiotic treatment $(P=0.9)$ or time elapsed since diagnosis $(P=0.9)$.

Table 2 Variables significantly associated with relapse according to the Cox regression analysis

\begin{tabular}{lll}
\hline & HR $(95 \% \mathrm{Cl})$ & $\mathrm{P}$ \\
\hline Symptoms longer than 3 months & $4.98(1.42-17.54)$ & 0.012 \\
Bone exposure & $12.66(3.15-49.26)$ & 0.0003 \\
Type of surgical treatment & & $<0.0001$ \\
None vs Debridement & $3.41(1.12-10.42)$ & 0.031 \\
None vs Debridement and flap & $33.27(7.80-141.88)$ & $<0.0001$ \\
Debridement vs Debridement and flap & $9.75(2.10-45.21)$ & 0.004 \\
\hline
\end{tabular}



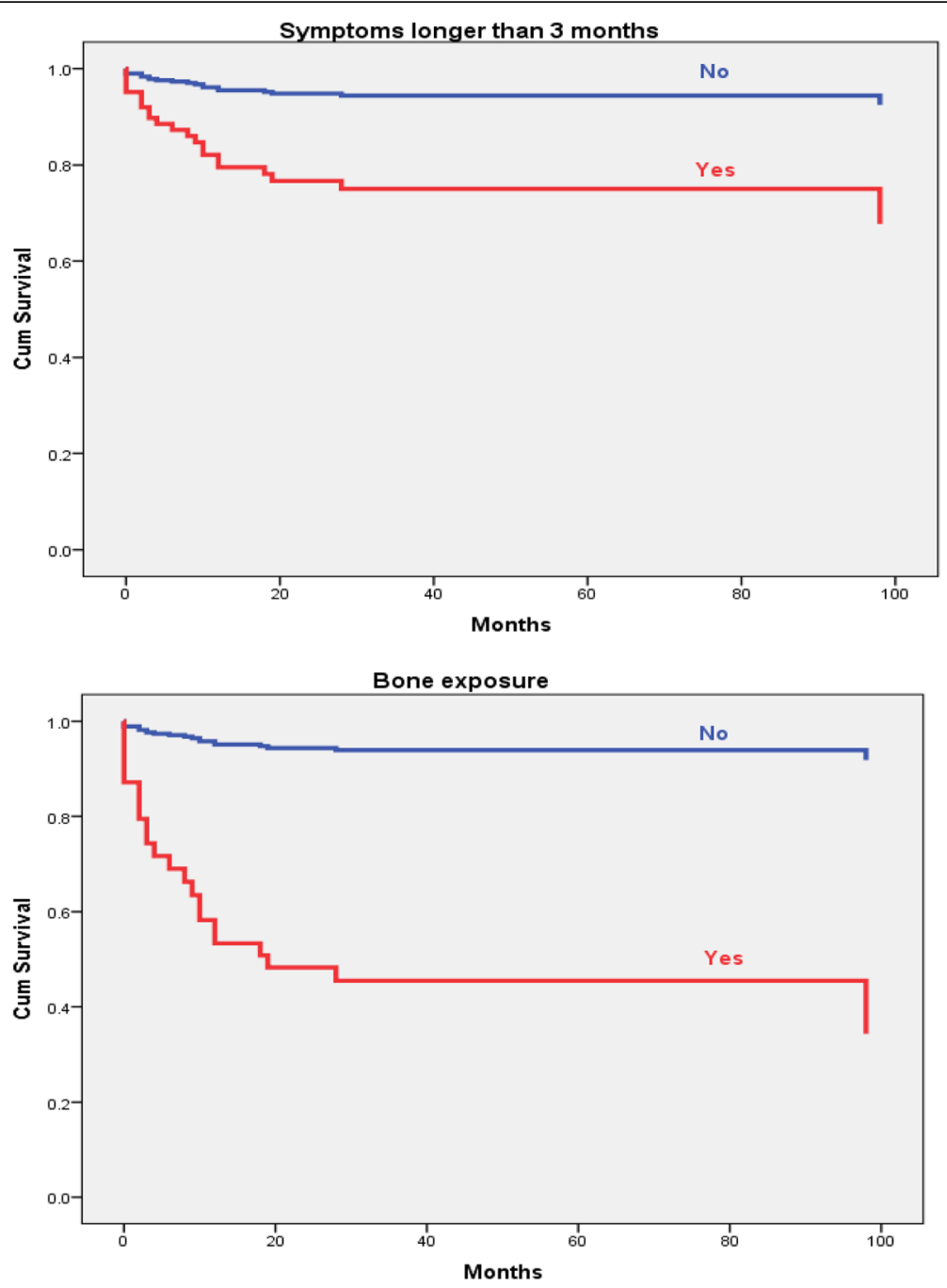

Type of surgery



Fig. 3 Variables independently associated with osteomyelitis relapse in the Cox regression analysis 


\section{Discussion}

We have analyzed the factors involved in the relapse of bacterial osteomyelitis of long bones in our series. Bone infection relapsed in $20.6 \%$ of the patients followed for more of one year, a slightly lower rate compared to that found in previous reports of adult osteomyelitis [6-11]. The parameters independently associated with osteomyelitis relapse in the multivariate analysis were duration of the infection for more than 3 months at presentation, bone exposure, mostly after an open fracture, and treatment other than surgical debridement with flap coverage. We have also developed a mathematical formula based on the predefined severity factors, and observed that the probability of relapse increased accordingly, being of 30.5, 40.6 and $45.5 \%$ for scores $\geq 1.5$, $\geq 2$, and $\geq 2.5$, respectively.

To our knowledge, only few clinical series focusing on the risk factors and outcome of bacterial osteomyelitis have been reported so far, one is a pediatric series of 83 children [13] while four other series included over 100 adult osteomyelitis patients each $[8,9,11,14]$ (Table 3). Ours is the second work in which a score made of the addition of clinical elements or points to predict osteomyelitis outcome is used and the only one in which this score is applied to adults, focuses exclusively on long bone osteomyelitis of different pathogenesis, analyzes relapses or is derived from the outcome. In fact. Roine's osteomyelitis score was applied to children with acute hematogenous osteomyelitis mostly, but not exclusively, of the long bones, focused to the development of diverse sequelae, not to relapses, and was pre-established, not derived from true results [13]. These authors considered as factors associated with osteomyelitis sequelae in children the following: axillary temperature $>37.4{ }^{\circ} \mathrm{C}$ for $>7$ days, marked local swelling or warmth for $>10$ days, marked local pain or limited motility for $>10$ days, additional surgical drainage after the initial one and more than one focus of osteomyelitis or septic shock in addition to high ESR and C-RP, and assigned 1 point to each of these pre-established factors. On the contrary, we calculated the relative weight of the different severity factors according to the outcome.

Our study includes adults with osteomyelitis of the long bones with a post-traumatic or post-surgical source in $82.8 \%$ of the cases. Therefore, we analyzed the presence of osteosynthesis material and bone exposure, because most of our patients suffered accidental fracture or surgical bone damage preceding the infection. In addition peripheral vascular involvement, diabetes and immunosuppression that we analyzed as potential osteomyelitis recurrence factors are rarely or not observed in children. In this regard, Tice et al $[8,9]$ found that peripheral vascular disease and/or diabetes were associated with osteomyelitis recurrence in a large series of mostly adult patients, with osteomyelitis mainly of the feet, hand and spine, and who also had a high prevalence of diabetes (38.1\%) (Table 3). We did not find such an association in our series composed of a relatively low number of patients with these two conditions $(<10 \%)$ and that excluded osteomyelitis of the feet, commonly seen in diabetic patients. On the other hand, Arias et al [11] found in a recent series of 129 osteomyelitis patients (91 with long-bone involvement) that the only factor significantly associated with recurrence was the specialty of the treating clinician (orthopedics as compared to infectologists).

Regarding the microorganism involved, $P$ aeruginosa [9] and MRSA or MSSA [13-17] have been associated with worse osteomyelitis outcomes. However, similarly to other authors that analyzed mainly long-bone osteomyelitis [11], we failed to find any association between any bacteria and osteomyelitis outcome.

In our study, bone debridement with flap coverage was associated with better osteomyelitis outcomes as compared to no surgery or exclusive debridement. The use of local muscle flaps in the treatment of osteomyelitis has been reported long ago to cover a large defect of soft tissue and bone, after debridement, with a success rate of above $95 \%$ $[18,19]$. Nowadays it is known that there are no differences between muscle and perforator fasciocutaneous flaps vascularization, and both of them, or even bone flaps, might be used for reconstruction in osteomyelitis after wide debridement.

Because there is a great variety of flaps, the election of muscle or fasciocutaneous, pedicled or free flaps must be made according to the characteristics of the defect to cover, of the recipient and of donor site morbidity [2026]. We analyzed 61 osteomyelitis patients treated with different types of flap coverage, and we did not observe differences regarding osteomyelitis relapse among the different flap modalities $(P=0.6)$, although any type of flap coverage, in addition to bone debridement, resulted in better osteomyelitis outcomes, as compared with no surgery $(P<0.0001)$ and bone debridement only $(P=$ 0.004). However, there are other promising techniques that were not used in our series, but could be applied for filling bone defects instead of, or in combination with, flaps like the use of bone substitutes, which have had a great development in the last years and could be used in association with locally-liberated antibiotics No studies comparing the results of bone substitutes vs. flap coverage have been reported so far but its combined use might reduce donor flap site morbidity and even avoid further surgical procedures Therefore, these promising techniques should be taken into account in the surgical management of osteomyelitis and bone reconstruction [27-29].

The optimal duration of antibiotic treatment in osteomyelitis still remains unclear. Traditionally osteomyelitis 
Table 3 Comparison of the demographic and clinical characteristics and recurrence factors in clinical studies of osteomyelitis

\begin{tabular}{|c|c|c|c|c|c|c|}
\hline & & $\begin{array}{l}\text { Roine [13] } \\
1996\end{array}$ & $\begin{array}{l}\text { Tice }[8,9] \\
2003\end{array}$ & $\begin{array}{l}\text { Arias [11] } \\
2015\end{array}$ & $\begin{array}{l}\operatorname{Lin}[14] \\
2016\end{array}$ & $\begin{array}{l}\text { Present series } \\
2017\end{array}$ \\
\hline \multicolumn{2}{|l|}{ No. patients (\% males) } & 83 (NS) & $454(65 \%)$ & $129(80.6 \%)$ & $108(75 \%)$ & $116(74.1 \%)$ \\
\hline \multicolumn{2}{|l|}{ Age group } & $\begin{array}{l}\text { Children (mean } \\
6.7 \mathrm{y} \text { ) }\end{array}$ & $\begin{array}{l}\text { Mostly adults (mean } \\
51 \mathrm{y} \text { ) }\end{array}$ & $\begin{array}{l}\text { Adults (range } \\
18-91 \text { y) }\end{array}$ & $\begin{array}{l}\text { Mostly adults } \\
\text { (median } 54 \text { y) }\end{array}$ & $\begin{array}{l}\text { Adults (mean } \\
53 \mathrm{y} \text { ) }\end{array}$ \\
\hline \multicolumn{2}{|l|}{ Country } & Costa Rica & USA & Colombia & Singapore & Spain \\
\hline \multicolumn{2}{|l|}{ Origin } & Hematogenous & Multiple & Multiple & Multiple & Multiple \\
\hline \multicolumn{2}{|l|}{ Post-traumatic (n, \%) } & $0(0 \%)$ & $409(90.1 \%)^{a}$ & $115(89.2 \%)$ & $42(38.9 \%)$ & $62(53.4 \%)$ \\
\hline \multicolumn{2}{|l|}{ Bones involved } & $\begin{array}{l}\text { Mostly long } \\
\text { bones }\end{array}$ & $\begin{array}{l}\text { Mostly non-long } \\
\text { bones }\end{array}$ & $\begin{array}{l}\text { Mostly long } \\
\text { bones }\end{array}$ & Mostly long bones & $\begin{array}{l}\text { Only long } \\
\text { bones }\end{array}$ \\
\hline \multicolumn{2}{|l|}{ S. aureus $(n, \%)^{b}$} & $41(49.4 \%)$ & $246(54.2 \%)$ & 49 (38.0\%) & $42(38.9 \%)$ & 48 (38.1\%) \\
\hline \multicolumn{2}{|l|}{ Diabetes } & NS & $173(38.1 \%)$ & $7(5.4 \%)$ & $58(53.7 \%)$ & $10(8.6 \%)$ \\
\hline \multicolumn{2}{|l|}{ Recurrence $(n, \%)$} & $5(6.0 \%)$ & $139(30.6 \%)$ & $30(23.3 \%)$ & $40(37.0 \%)$ & $26(20.6 \%)$ \\
\hline \multicolumn{2}{|l|}{ Mean follow-up (months) } & 1.5 or $14^{c}$ & 28.3 & 12 & 23,4 & 67.1 \\
\hline \multirow[t]{13}{*}{$\begin{array}{l}\text { Factors associated with } \\
\text { recurrence }\end{array}$} & $\begin{array}{l}\text { Microorganisms } \\
\text { involved }\end{array}$ & Saureus $^{d}$ & $P$ aeruginosa & No & MRSA & No \\
\hline & Antibiotic type & No ${ }^{d}$ & Yes (vancomycin) ${ }^{e}$ & No & NS & No \\
\hline & Antibiotic duration & No ${ }^{d}$ & NS & No & No & No \\
\hline & Age & No ${ }^{d}$ & No (> 70 y) & No & No & No \\
\hline & Diabetes & NS $^{d}$ & Yes & No & No & No \\
\hline & $\begin{array}{l}\text { Peripheral vascular } \\
\text { disease }\end{array}$ & $N A^{d}$ & Yes & No & No & No \\
\hline & Long bones & NS $^{d}$ & NS & No & Yes (lower limbs) & No \\
\hline & Fracture & $N A^{d}$ & NS & No & No & No \\
\hline & Symptoms duration & No ${ }^{d}$ & NS & NS & NS & $\begin{array}{l}\text { Yes (> } 3 \\
\text { months) }\end{array}$ \\
\hline & Bone exposure & $N A^{d}$ & NS & No & No & Yes \\
\hline & Type of surgery & No ${ }^{d}$ & NS & NS & No & Yes \\
\hline & C-RP & Yes $^{d}$ & NS & NS & No & No \\
\hline & ESR & No ${ }^{d}$ & NS & NS & Yes $(\geq 20 \mathrm{~mm} / \mathrm{h})$ & No \\
\hline
\end{tabular}

NA denotes not applicable, NS not studied, MSSA methicillin-susceptible Staphylococcus aureus, MRSA methicillin-resistant Staphylococcus aureus, C-RP C-reactive protein, ESR erythrocyte sedimentation rate

${ }^{\text {a}}$ Described as associated with wounds

${ }^{\mathrm{b}}$ Respect to the total number of patients

CAll patients were followed-up for a mean of at least 1,5 months, and $78 \%$ of them for a mean of 14 months

dFactors associated with sequelae (28 patients, $33.7 \%)$; data for recurrence are not provided

eOnly in staphylococcal infections

has been treated with 4-6 weeks of parenteral antibiotics after definitive debridement surgery [4-7]. A review of the literature regarding the ideal duration of parenteral antimicrobial therapy concluded that the critical point regarding cure or recurrence relies more on the surgical technique than on the antimicrobial time frame [30]. Also, there is no evidence that prolonged parenteral antibiotics will improve the penetration in the necrotic bone. However, a vascularized flap would allow the establishment of better bone blood supply and better antibiotic release in the infected bone, allowing a shorter duration of treatment. An adequate surgical approach.

combining complete debridement and a well-vascularized flap coverage, both factors associated with better outcomes in our series, would facilitate shorter intravenous therapies, even of only 2 weeks [30-32].

The type of antimicrobials used, and the duration of intravenous or combined oral and intravenous therapies did not associate with osteomyelitis relapse in our study. However, it should be considered that the mean duration of intravenous therapy in our series (about 4 weeks) was similar in both groups and large enough to ensure sufficient antibiotic therapy. Therefore, any possible impact of treatment duration on the outcome would be minimized. Consequently, we cannot completely exclude that shorter periods of treatment could have an influence on the relapse rate. On the other hand, the similarity between the two groups regarding 
the duration of antibiotic therapy contributes to exclude this potentially important interacting factor and to stress the value of the other factors associated with relapse found in our study.

Our osteomyelitis series differs in several facts from those previously published (Table 3 ). It includes a large number of cases of bacterial osteomyelitis mostly of post-traumatic or post-surgical origin, limited exclusively to long bones of adults, with the longest follow-up of those published (mean 67.1 months), and it is also the only one in which different surgical approaches to osteomyelitis are compared. In addition, we bring forward here an osteomyelitis recurrence score that might be helpful to the clinicians involved in the care of these patients to predict at presentation the risk of relapse.

Apart from symptoms duration and bone exposure, we did not find that other severity factors considered individually were significantly associated with relapse, such as the presence of osteosynthesis material, vascular compromise, diabetes, multiresistant or polymicrobial infection or underlying immunosuppression, although the presence of at least some of them seemed to elicit somewhat worse outcomes in the Kaplan-Meier survival curves. Therefore, we cannot entirely dismiss that statistically significant differences could exist if larger series with more relapse cases were analyzed. Interestingly, no differences regarding gender were observed in the previously reported series, although women had appreciably worse outcomes than men in the Cox regression analysis, differences that were close to the statistical significance limit $(P=0.056)$.

Classical laboratory parameters, such as ESR and C-RP, were not valid to discriminate between those patients with or without infection relapse when determined at baseline in our series. However, the value of their sequential determination during follow-up has been described in children with acute hematogenous osteomyelitis and also in adults [13, 14, 33, 34].

Our study has several limitations, including those related to the retrospective studies, the relatively reduced sample size to analyze subgroups and the long period of inclusion, almost unavoidable in a single-center series. However, the sample size was the highest among the main series reviewed regarding the number of patients with long bone osteomyelitis from one single center, and large enough to detect significant differences in several relevant parameters. On the other hand, the single-center series ensured a greater homogeneity in the evaluation and management of the patients, the very long period of follow-up ensured the detection of late relapses and, finally, the long period of recruitment did not seem to bias the results as the year of diagnosis did not have any significant influence on the outcome $(P=0.8)$.
From our series, limited exclusively to long bone osteomyelitis in adults, we conclude that symptoms present for longer than 3 months, bone exposure and treatment other than surgical debridement with free or pedicled flaps are risk factors for osteomyelitis relapse. Therefore, the other modalities of medical or surgical treatment analyzed should be considered suboptimal. Bone exposure and duration of osteomyelitis favor poorer outcomes, regardless of the type of treatment used, constitutes therefore easy-to-detect markers of severity, and should be considered in any patient with long bone osteomyelitis. Further studies are needed to validate these severity factors and to design treatment strategies focused on a better management of these especially difficult-to-treat cases.

\section{Conclusions}

Osteomyelitis extending for $>3$ months, bone exposure and treatment other than surgical debridement with muscular flap are risk factors for osteomyelitis relapse.

\begin{abstract}
Abbreviations
Cl: Confidence interval; C-RP: C-reactive protein; CT: Computed tomography $(C T)$; ESR: Erythrocyte sedimentation rate; MRI: Magnetic resonance imaging; MRSA: Methicillin-resistant (MRSA); MSSA: Methicillin-susceptible

Staphylococcus aureus; ROC: Receiver operating characteristic curve
\end{abstract}

\section{Acknowledgements}

Not applicable.

\section{Funding}

This study has no funding.

\section{Availability of data and materials}

The datasets generated and analysed during the current study are not publicly available due to privacy but are available from the corresponding author on reasonable request.

\section{Authors' contributions}

EGP reviewed clinical charts patients and collected the data, JC did the statistical analysis of the data and edited the manuscript, JAC and DC reviewed clinical charts and revised critically the manuscript and VA designed the study, reviewed clinical charts, collected data and wrote the manuscript. All the authors have read and approved the manuscript.

\section{Authors' information}

These results were presented in part at the ASM Microbe Meeting, New Orleans, LA, 1-5 June 2017; abstract \# 243.

\section{Ethics approval and consent to participate}

The study was approved by the Research Ethics Committee of the Principado de Asturias. Because this was a retrospective study based on medical records since 1994, no individual informed consent from each participant could be obtained. However, data were analyzed anonymously, and the study was approved by the Research Ethics Committee of the Principado de Asturias.

\section{Consent for publication}

Not applicable.

Competing interests

The authors declare that they have no competing interests. 


\section{Publisher's Note}

Springer Nature remains neutral with regard to jurisdictional claims in published maps and institutional affiliations.

\begin{abstract}
Author details
'Plastic Surgery Service, Hospital Universitario Central de Asturias (HUCA), Oviedo, Asturias, Spain. ${ }^{2}$ Infectious Diseases Unit, Hospital de Galdácano, Galdacano, Vizcaya, Spain. ${ }^{3}$ Infectious Diseases Unit, Hospital Universitario Central de Asturias (HUCA), Oviedo University School of Medicine, Oviedo, Spain. ${ }^{4}$ Group of Translational Research in Infectious Diseases, Instituto de Investigación Sanitaria del Principado de Asturias (ISPA), Asturias, Spain.
\end{abstract}

Received: 28 December 2017 Accepted: 23 November 2018

Published online: 07 December 2018

\section{References}

1. Cierny G, Mader JT. Adult chronic osteomyelitis. Orthopedics. 1984;7:1557-64.

2. Roesgen M, Hierholzer G, Hax PM. Post-traumatic osteomyelitis. Pathophysiology and management. Arch Orthop Trauma Surg. 1989;108:1-9.

3. Kindsfater $\mathrm{K}$, Jonassen EA. Osteomyelitis in grade II and III open tibia fractures with late debridement. J Orthop Trauma. 1995;9:121-7.

4. Lew DP, Waldvogel FA. Osteomyelitis. N Engl J Med. 1997;336:999-1007.

5. Lew DP, Waldvogel FA. Osteomyelitis. Lancet. 2004;364:369-79.

6. Calhoun JH, Manring MM, Shirtliff M. Osteomyelitis of the long bones. Semin Plast Surg. 2009;23:59-72.

7. Chihara S, Segreti J. Osteomyelitis. Dis Month. 2010;56:5-31.

8. Tice AD, Hoaglund PA, Shoultz DA. Outcomes of osteomyelitis among patients treated with outpatient parenteral antimicrobial therapy. Am J Med. 2003;114:723-8.

9. Tice AD, Hoaglund PA, Shoultz DA. Risk factors and treatment outcomes in osteomyelitis. J Antimicrob Chemother. 2003;51:1261-8.

10. Lipsky BA, Berendt AR, Deery HG, Embil JM, Joseph WS, Karchmer AW, et al. Diagnosis and treatment of diabetic foot infections. Plast Reconstr Surg. 2006;117(7 Suppl):212S-38S.

11. Arias Arias C, Tamayo Betancur MC, Pinzón MA, Cardona Arango D, Capataz Taffur CA, Correa Prada E. Differences in the clinical outcome of osteomyelitis by treating specialty: Orthopedics or Infectology. PLoS One. 2015;10:e0144736.

12. Gustilo RB, Anderson JT. Prevention of infection in the treatment of one thousand and twenty-five open fractures of long bones: retrospective and prospective analyses. J Bone Joint Surg Am. 1976;58:453-8.

13. Roine I, Arguedas A, Faingezicht I, Rodriguez F. Early detection of sequelaeprone osteomyelitis in children with use of simple clinical and laboratory criteria. Clin Infect Dis. 1997;24:849-53.

14. Lin Z, Vasudevan A, Tambyah PA. Use of erythrocyte sedimentation rate and C-reactive protein to predict osteomyelitis recurrence. J Orthop Surg. 2016; 24:77-83.

15. Park KH, Cho OH, Lee JH, Park JS, Ryu KN, Park SY, et al. Optimal duration of antibiotic therapy in patients with hematogenous vertebral osteomyelitis at low risk and high risk of recurrence. Clin Infect Dis. 2016;62:1262-9.

16. Dombrowski JC, Winston LG. Clinical failures of appropriately-treated methicillin-resistant Staphylococcus aureus infections. J Inf 2008;57:110-5.

17. Inoue S, Moriyama T, Horinouchi Y, Tachibana T, Okada F, Maruo K, et al, Comparison of clinical features and outcomes of Staphylococcus aureus vertebral osteomyelitis caused by methicillin-resistant and methicillinsensitive strains. SpringerPlus. 2013;2:283.

18. Fitzgerald RH Jr, Ruttle PE, Arnold PG, Kelly PJ, Irons GB. Local muscle flaps in the treatment of chronic osteomyelitis. J Bone Joint Surg Am. 1985;67: 175-85.

19. Anthony JP, Mathes SJ, Alpert BS. The muscle flap in the treatment of chronic lower extremity osteomyelitis: results in patients over 5 years after treatment. Plast Reconstr Surg. 1991:88:311-8.

20. Heppert V, Becker S, Winkler H, Wentzensen A. Myocutaneous versus fasciocutaneous free flaps in the treatment of lower leg osteitis. Eur J Orthop Surg Traumatol. 1995;5:27-31.

21. Verhelle N, Van Zele D, Liboutton L, Heymans O. How to deal with bone exposure and osteomyelitis: an overview. Acta Orthop Belg. 2003;69:481-94.

22. Dinh P, Hutchinson BK, Zalavras C, Stevanovic MV. Reconstruction of osteomyelitis defects. Semin Plast Surg. 2009;23:108-18.
23. Hong JP, Shin HW, Kim JJ, Wei FC, Chung YK. The use of anterolateral thigh perforator flaps in chronic osteomyelitis of the lower extremity. Plast Reconstr Surg. 2005;115:142-8.

24. Salgado CJ, Mardini S, Jamali AA, Ortiz J, Gonzales R, Chen HC. Muscle versus nonmuscle flaps in the reconstruction of chronic osteomyelitis defects. Plast Reconstr Surg. 2006;118:1401-11.

25. Klebuc M, Menn Z. Muscle flaps and their role in limb salvage. Methodist Debakey Cardiovasc J. 2013;9:95-9.

26. Paro J, Chiou G, Sen SK. Comparing muscle and fasciocutaneous free flaps in lower extremity reconstruction--Does it matter? Ann Plast Surg. 2016; 76(Suppl 3):S213-5.

27. Inzana JA, Schwarz EM, Kates SL, Awad HA. Biomaterials approaches to treating implant-associated osteomyelitis. Biomaterials. 2016;81:58-71.

28. Aurégan JC, Bégué T. Bioactive glass for long bone infection: a systematic review. Injury. 2015:46(Suppl 8):S3-7.

29. Posadowska U, Brzychczy-Wloch M, Pamula E. Injectable gellan gum-based nanoparticles-loaded system for the local delivery of vancomycin in osteomyelitis treatment. J Mater Sci Mater Med. 2016;27:9. https://doi.org/ 10.1007/s10856-015-5604-2.

30. Haidar R, Der Boghossian A, Atiyeh B. Duration of post-surgical antibiotics in chronic osteomyelitis: empiric or evidence-based? Int J Infect Dis. 2010;14: e752-8.

31. Rod-Fleury T, Dunkel N, Assal M, Rohner P, Tahinzti P, Bernard L, et al. Duration of post-surgical antibiotic therapy for adult chronic osteomyelitis.A single-Centre experience. Int Orthop. 2011;35:1725-31.

32. Spellberg B, Lipsky BA. Systemic antibiotic therapy for chronic osteomyelitis in adults. Clin Infect Dis. 2012;54:393-407.

33. Unkila-Kallio L, Kallio MJ, Eskola J, Peltola H. Serum C-reactive protein, erythrocyte sedimentation rate, and white blood cell count in acute hematogenous osteomyelitis of children. Pediatrics. 1994;93:59-62.

34. Crosby LA, Powell DA. The potential value of the sedimentation rate in monitoring treatment outcome in puncture-wound-related Pseudomonas osteomyelitis. Clin Orthop Relat Res. 1984;188:168-72.

Ready to submit your research? Choose BMC and benefit from:

- fast, convenient online submission

- thorough peer review by experienced researchers in your field

- rapid publication on acceptance

- support for research data, including large and complex data types

- gold Open Access which fosters wider collaboration and increased citations

- maximum visibility for your research: over $100 \mathrm{M}$ website views per year

At $\mathrm{BMC}$, research is always in progress.

Learn more biomedcentral.com/submissions 